\title{
Proventricular Dilatation Disease Associated with Avian Bornavirus Infection in a Citron-Crested Cockatoo that Was Born and Hand-Reared in Japan
}

\author{
Hirohito OGAWA ${ }^{1) * *}$, Yasuyuki SANADA ${ }^{2)}$, Naoko SANADA ${ }^{2)}$, Megumi KUDO ${ }^{3)}$, Kotaro TUCHIYA ${ }^{1)}$, \\ Toshiaki KODAMA ${ }^{1)}$ and Koji UETSUKA ${ }^{1) *}$ \\ ${ }^{1)}$ Nippon Institute for Biological Science, 9-2221-1 Shinmachi, Ome, Tokyo 198-0024, 2) Bird's Hospital-BIRD HOUSE, 3-20-2 \\ Akehara, Kashiwa, Chiba 277-0843 and ${ }^{3)}$ Sapporo Bird's Clinic, Minami-2, Nishi-7, Chuo-ku, Sapporo, Hokkaido 060-0062, Japan
}

(Received 19 October 2010/Accepted 14 January 2011/Published online in J-STAGE 28 January 2011)

ABSTRACT. A 5-month-old female Citron-crested Cockatoo (Cacatua sulphurea citrinocristata) that was born and hand-reared in Japan died with suspected proventricular dilatation disease (PDD). Macroscopic and microscopic examinations of the bird revealed characteristic features of PDD, i.e., distention of the proventriculus and infiltration of lymphocytes and plasma cells in ganglia of various organs and in central and peripheral nerves. A linkage of this PDD case to infection with avian bornavirus (ABV) was documented by RTPCR amplification of the virus genomes from the affected bird. Phylogenetic analysis revealed that the ABV identified in this study clustered into the genotype 2, which is one of the dominant ABV genotypes worldwide. To the best of our knowledge, this is the first report of a natural case of PDD associated with ABV infection in Japan.

KEY WORDS: avian bornavirus, Citron-crested cockatoo, PDD, proventricular dilatation disease.

J. Vet. Med. Sci. 73(6): 837-840, 2011

Proventricular dilatation disease (PDD) was first reported in macaws in the late 1970s and early 1980s [1,5], and as a result, it is known as macaw wasting disease. The name, PDD, is derived from the characteristic feature of the disease, i.e., dilatation of the proventriculus. The most common clinical signs of PDD are depression, weight loss, regurgitation, central nervous system signs such as ataxia, tremors and seizures and/or passage of undigested seeds in the feces, indicating a malabsorptive or maldigestive disorder $[1,5]$. Definitive diagnosis of PDD relies on characteristic histopathologies of lymphoplasmacytic infiltration in nerves and ganglia of the proventriculus, ventriculus and other gastrointestinal tract. Similar infiltrations are also often seen in the brain, spinal cord, peripheral nerves, heart and adrenal glands $[1,5]$.

Although the cause of PDD has been unknown for many years, major advances were recently made in determining the etiology of PDD: Pyrosequencing, PCR and microarray analyses of PDD-affected birds identified a novel negative single-stranded RNA virus that was named avian bornavirus (ABV) within the family Bornaviridae [7]. Since then, ABV has been detected in various psittacine species with PDD from the U.S.A., Australia, Israel, Germany, Austria, Switzerland and Hungary $[6-10,13,15]$ and in a nonpsittacine bird, a canary (Serinus canaria), from Austria [16]. It has also been shown that PDD can be induced in cockatiels (Nymphicus hollandicus) and Patagonian conures (Cyanoliseus patagonus) by experimental ABV infections [3, 4], implying that $\mathrm{ABV}$ is the etiologic agent of PDD.

\footnotetext{
* Correspondence to: Uetsuka, K., Nippon Institute for Biological Science, 9-2221-1 Shinmachi, Ome, Tokyo 198-0024, Japan. e-mail: koji_ue@nibs.or.jp

**PRESENT ADDRESS: Hokudai Center for Zoonosis Control in Zambia, School of Veterinary Medicine, The University of Zambia, P.O. Box 32379, Lusaka, Zambia.
}

Since PDD was first reported in macaws, PDD has been diagnosed in more than 50 species of Psittaciformes worldwide, and similar symptoms have also been reported in the wild Canada goose (Branta Canadensis), canary, greenfinch (Carduelis chloris), long-wattled umbrellabird (Cephalopterus penduliger) and bearded barbet (Lybius dubius) [2, 11]. Regardless, the incidence of PDD has not previously been reported in Japan. Here, we report the first natural case of PDD in a Citron-crested cockatoo (Cacatua sulphurea citrinocristata) that was born and hand-reared in Japan.

A 5-month-old female Citron-crested cockatoo that died of suspected PDD was donated to the Companion Bird Laboratories (Kashiwa, Chiba, Japan) for pathological examination. A complete necropsy was performed, and selected organs were collected and fixed in 10\% neutral buffered formalin. Paraffin sections were cut at $3 \mu \mathrm{m}$ and stained with hematoxylin and eosin (HE). Portions of major organs were also collected and stored at $-20^{\circ} \mathrm{C}$.

At necropsy, the cockatoo weighed merely $292 \mathrm{~g}$ and was considered to be in a poor condition. Grossly, prominent lesions were observed in the proventriculus, which was markedly distended and thin walled (Fig. 1). A yellowish brown or yellowish green semi-paste of undigested food was also present in the upper gastrointestinal tract including the esophagus, crop, proventriculus and ventriculus. The small intestine was also distended and contained yellowish green content. The liver was dark red and enlarged. The spleen was fawn in color. The lung showed severe edema bilaterally, and a black region was observed dorsolaterally. A large amount of yellowish white semi-paste liquid was present in the trachea.

Histological examination revealed lymphocyte and plasma cell infiltration in ganglia of various organs and in central and peripheral nerves (Table 1 and Fig. 2A-F). 


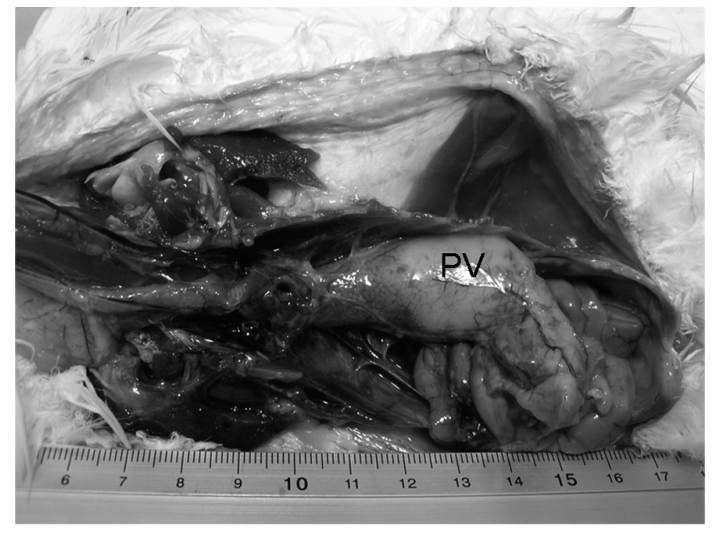

Fig. 1. Distended proventriculus (PV) at necropsy of the Citron-crested cockatoo.

Table 1. Degree of microscopic lesions in the ganglia of various organs and in central and peripheral nerves

\begin{tabular}{|c|c|}
\hline Organ & Degree $^{a)}$ \\
\hline Lung & + \\
\hline Thyroid gland & + \\
\hline Heart & + to ++ \\
\hline Esophagus/Crop & + \\
\hline Proventriculus & ++ \\
\hline Ventriculus & ++ \\
\hline Duodenum & + \\
\hline Jejunum/Ileum & ++ to +++ \\
\hline Cloaca & ++ to +++ \\
\hline Spleen & ++ \\
\hline Kidney & + \\
\hline Adrenal gland & + to ++ \\
\hline Sciatic nerve & + to ++ \\
\hline Branchial nerve & + to ++ \\
\hline Brain & + \\
\hline Spinal cord & + \\
\hline
\end{tabular}

a) Scoring was as follows: +++ , sever; ++ , moderate; and + , mild.

Other remarkable findings included myocardial necrosis with hemorrhage in the right ventricle (Fig. 2G) and diffuse infiltrations of lymphocytes and plasma cells in the mucosal lamina propria of the jejunum (Fig. 2H). Severe diffuse congestion and edema were also present in the lung and liver. Based on these histopathological findings characteristic to PDD $[1,5]$, the death of this cockatoo was diagnosed as resulting from $\mathrm{PDD}$.

To investigate if $\mathrm{ABV}$ infection was involved in this case of PDD, we attempted to amplify the $\mathrm{N}$ and $\mathrm{L}$ genes of ABV from the cerebrum, lung, liver, spleen, kidney and intestine of the bird by RT-PCR using SuperScript ${ }^{\mathrm{TM}}$ One-Step RTPCR with Platinum Taq (Invitrogen Co., Carlsbad, CA, U.S.A.). For amplification of the viral $\mathrm{N}$ and $\mathrm{L}$ genes, we used the following sets of primers described previously [7]: ABV_NconsensusF (5'-CCHCATGAGGCTATWGATTG-
GATTAACG-3') and ABV_NconsensusR (5'-GCMCGGTAGCCNGCCATTGT DGG-3') for the $\mathrm{N}$ gene and ABV_LconsensusF (5' - CGCCTCGGAAGGTGGTCGG3') and ABV_LconsensusR (5'-GGCAYCAYCKACTCTTRAYYGTRTCAGC-3') for the L gene. Among the six tissues analyzed, the $\mathrm{N}$ and $\mathrm{L}$ genes of $\mathrm{ABV}$ were readily amplified from the cerebrum, but neither the $\mathrm{N}$ nor L gene was amplified from the other tissues. The resultant amplicons from the cerebrum were subjected to direct sequencing, and the sequences obtained were edited using GenetyxMac version 15.0.1 (Genetyx Co., Tokyo, Japan) and Genetyx-Mac/ATSQ version 5.1 (Genetyx Co.). Compared with the $\mathrm{N}$ gene sequences of thirteen published ABVs, the $\mathrm{N}$ genes derived from the cerebrum (398 bp, GenBank accession number $A B 537974$ ) had 72 to $97 \%$ and 86 to $100 \%$ nucleotide and amino acid homologies, respectively. Similarly, the L genes derived from the cerebrum (411 bp, GenBank accession number AB537975) had 75 to $97 \%$ and 85 to $99 \%$ nucleotide and amino acid homologies, respectively, with the $\mathrm{L}$ genes of fourteen published ABVs. It has been shown that ABV from various psittacine species exhibits high genetic variation, and at least five distinct ABV genotypes have been identified (genotype 1-5, Fig. 3). Phylogenetic analysis based on the partial $\mathrm{N}$ gene sequences revealed that the ABV identified in this study (1307 in Fig. 3 ) clustered into ABV genotype 2, which is one of the dominant ABV genotypes worldwide $[14,15]$. Seventeen serial blind passages were attempted to isolate ABV from $10 \%$ cerebrum homogenate in Japanese quail fibroblast cells (QE-1 cells), but unfortunately, ABV genomic RNA was not detected by RT-PCR.

To the best of our knowledge, this is the first case report of PDD associated with ABV infection in Japan. The Citron-crested Cockatoo diagnosed with PDD was born and hand-reared in Japan and died early at five months of age. There were no histopathologic lesions in the cerebrum, although ABV genomic RNA was detected in this case. In general, tissues in which viral RNA is detected by RT-PCR show histopathologic lesions attributable to PDD. However, a recent report also documented the same result in the cerebrum [12], and the reason for these results is unknown. Little is known about the mode of transmission of ABV, including this reported case, but previous studies have suggested horizontal transmission of the virus via oral and/or respiratory routes [13]. A recent report of a PDD outbreak by $\mathrm{ABV}$ transmission between two breeder aviaries [8] as well as the presence of healthy or subclinical carriers of $\mathrm{ABV}$ in several species [9] suggests that ABV is highly transmissible among psittacines and other avian species. Although this is the first report of PDD associated with ABV infection in Japan, the virus may already have spread among psittacine and other species in domestic aviaries to some extent. As a first step to prevent spread of ABV and outbreak of PDD in Japan, an epidemiological survey of $\mathrm{ABV}$ is warranted. 

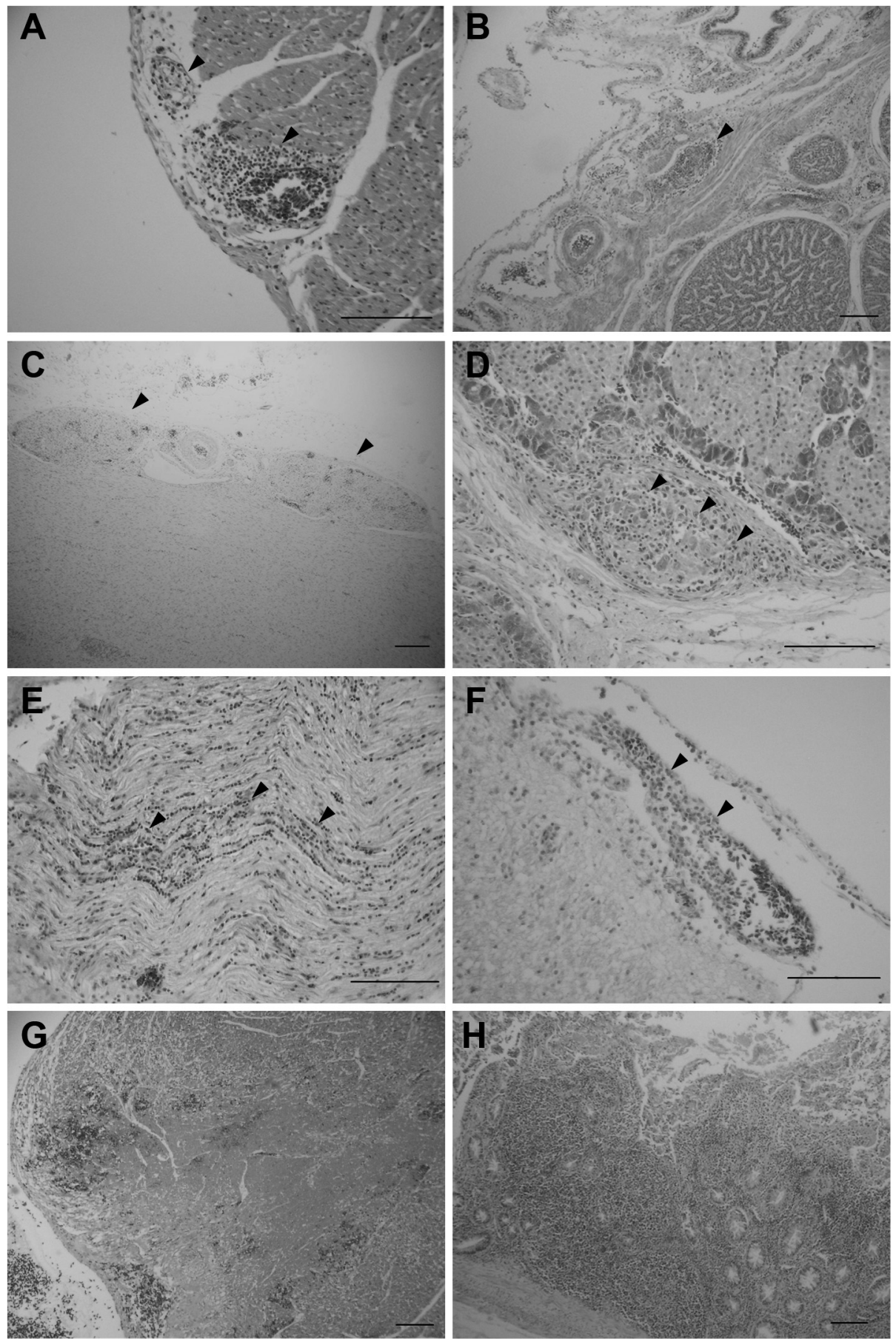

Fig. 2. Lymphocytes and plasma cells infiltrate the epicardial ganglion (A), serosal ganglion of the proventriculus (B) and ventriculus (C), periadrenal ganglion (D), brachial nerve (E) and meninx of the optic tectum (F). Severe myocardial necrosis with hemorrhage of the right ventricular wall (G). Lymphocytes and plasma cells infiltrate the mucosal lamina propria of the jejunum $(\mathrm{H})$. Arrowheads indicate the portions of lymphocyte and plasma cell infiltration. HE. Bar $=100 \mu \mathrm{m}$.

\section{REFERENCES}

1. Berhane, Y., Smith, D. A., Newman, S., Taylor, M., Nagy, E.,
Binnington, B. and Hunter, B. 2001. Peripheral neuritis in psittacine birds with proventricular dilatation disease. Avian Pathol. 30: 563-570.

2. Daoust, P. Y., Julian, R. J., Yason, C. V. and Artsob, H. 1991. 


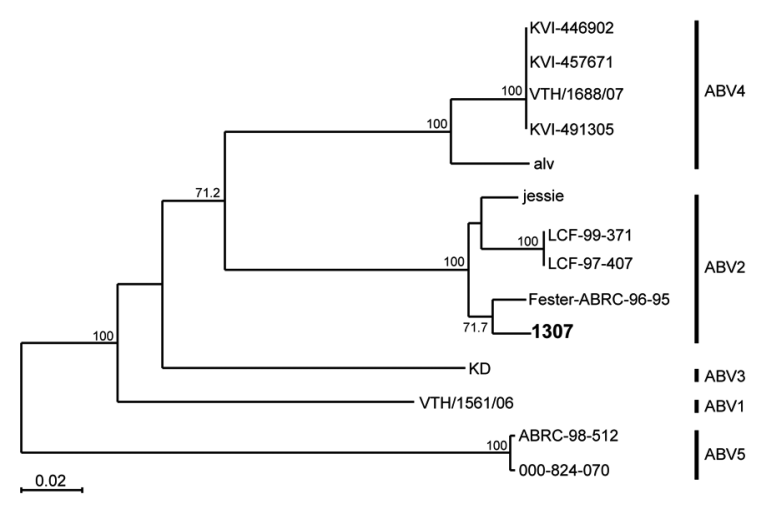

Fig. 3. A phylogenetic tree based on the $\mathrm{N}$ gene sequences of ABV. The $\mathrm{N}$ gene identified in this study (1307) is indicated in bold. The reference sequences for the $\mathrm{N}$ gene of $\mathrm{AEV}$ were obtained from the GenBank database. Numbers at nodes are bootstrap probabilities that were calculated using 1,000 replicates and indicate confidence limits of $>70 \%$.

Proventricular impaction associated with nonsuppurative encephalomyelitis and ganglioneuritis in two Canada geese. $J$. Wildl. Dis. 27: 513-517.

3. Gancz, A. Y., Kistler, A. L., Greninger, A. L., Farnoushi, Y., Mechani, S., Perl, S., Berkowitz, A., Perez, N., Clubb, S., DeRisi, J. L., Ganem, D. and Lublin, A. 2009. Experimental induction of proventricular dilatation disease in cockatiels (Nymphicus hollandicus) inoculated with brain homogenates containing avian bornavirus 4. Virol. J. 6: 100.

4. Gray, P., Hoppes, S., Suchodolski, P., Mirhosseini, N., Payne, S., Villanueva, I., Shivaprasad, H. L., Honkavuori, K. S., Lipkin, W. I., Briese, T., Reddy, S. M. and Tizard, I. 2010. Use of avian bornavirus isolates to induce proventricular dilatation disease in conures. Emerg. Infect. Dis. 16: 473-479.

5. Gregory, C. R. 1995. Proventricular dilatation syndrome. pp. 439-450. In: Avian Viruses: Function and Control, 1st ed. (Ritchie, B. W. ed.), Wingers Publishing, Florida.

6. Honkavuori, K. S., Shivaprasad, H. L., Williams, B. L., Quan, P. L., Hornig, M., Street, C., Palacios, G., Hutchison, S. K., Franca, M., Egholm, M., Briese, T. and Lipkin, W. I. 2008. Novel borna virus in psittacine birds with proventricular dilatation disease. Emerg. Infect. Dis. 14: 1883-1886.

7. Kistler, A. L., Gancz, A., Clubb, S., Skewes-Cox, P., Fischer,
K., Sorber, K., Chiu, C. Y., Lublin, A., Mechani, S., Farnoushi, Y., Greninger, A., Wen, C. C., Karlene, S. B., Ganem, D. and DeRisi, J. L. 2008. Recovery of divergent avian bornaviruses from cases of proventricular dilatation disease: identification of a candidate etiologic agent. Virol. J. 5: 88.

8. Kistler, A. L., Smith, J. M., Greninger, A. L., Derisi, J. L. and Ganem, D. 2010. Analysis of naturally occurring avian bornavirus infection and transmission during an outbreak of proventricular dilatation disease among captive psittacine birds. J. Virol. 84: 2176-2179.

9. Lierz, M., Hafez, H. M., Honkavuori, K. S., Gruber, A. D., Olias, P., Abdelwhab, E. M., Kohls, A., Lipkin, W. I., Briese, T. and Hauck, R. 2009. Anatomical distribution of avian bornavirus in parrots, its occurrence in clinically healthy birds and ABV-antibody detection. Avian Pathol. 38: 491-496.

10. Ouyang, N., Storts, R., Tian, Y., Wigle, W., Villanueva, I., Mirhosseini, N., Payne, S., Gray, P. and Tizard, I. 2009. Histopathology and the detection of avian bornavirus in the nervous system of birds diagnosed with proventricular dilatation disease. Avian Pathol. 38: 393-401.

11. Perpinan, D., Fernandez-Bellon, H., Lopez, C. and Ramis, A. 2007. Lymphoplasmacytic myenteric, subepicardial, and pulmonary ganglioneuritis in four nonpsittacine birds. J. Avian Med. Surg. 21: 210-214.

12. Raghav, R., Taylor, M., Delay, J., Ojkic, D., Pearl, D. L., Kistler, A. L., Derisi, J. L., Ganem, D. and Smith, D. A. 2010. Avian bornavirus is present in many tissues of psittacine birds with histopathologic evidence of proventricular dilatation disease. J. Vet. Diagn. Invest. 22: 495-508.

13. Rinder, M., Ackermann, A., Kempf, H., Kaspers, B., Korbel, R. and Staeheli, P. 2009. Broad tissue and cell tropism of avian bornavirus in parrots with proventricular dilatation disease. $J$. Virol. 83: 5401-5407.

14. Staeheli, P., Rinder, M. and Kaspers, B. 2010. Avian bornavirus associated with fatal disease in psittacine birds. J. Virol. 84: 6269-6275.

15. Weissenbock, H., Bakonyi, T., Sekulin, K., Ehrensperger, F., Doneley, R. J., Durrwald, R., Hoop, R., Erdelyi, K., Gal, J., Kolodziejek, J. and Nowotny, N. 2009. Avian bornaviruses in psittacine birds from Europe and Australia with proventricular dilatation disease. Emerg. Infect. Dis. 15: 1453-1459.

16. Weissenbock, H., Sekulin, K., Bakonyi, T., Hogler, S. and Nowotny, N. 2009. Novel avian bornavirus in a nonpsittacine species (Canary; Serinus canaria) with enteric ganglioneuritis and encephalitis. $J$. Virol. 83: 11367-11371. 